\title{
Profil Penderita Stenosis Mitral Reumatik di RSUP Dr. M. Djamil Padang Tahun 2012-2016
}

\author{
Mentari Brillianti Permataranny ${ }^{1}$, Mefri Yanni $^{2}$, Hendra Permana $^{3}$
}

\begin{abstract}
Abstrak
Penyakit Jantung Reumatik (PJR) masih memiliki prevalensi serta tingkat morbiditas dan mortalitas yang tinggi di negara berkembang, termasuk di Indonesia. Stenosis Mitral Reumatik (SMR) merupakan salah satu penyakit katup jantung yang paling sering terjadi pada PJR, namun data penelitian yang tersedia mengenai SMR di Indonesia masih sedikit. Tujuan penelitian ini adalah untuk mengetahui profil penderita SMR di RSUP Dr. M. Djamil Padang tahun 2012 sampai 2016. Ini adalah studi deskriptif dengan pendekatan retrospektif yang dilaksanakan sejak September 2017 sampai Januari 2018 di RSUP. Dr. M. Djamil Padang di bagian rekam medis. Yang memenuhi kriteria inklusi dijadikan sampel penelitian dengan menggunakan teknik total sampling. Proporsi SMR pada penelitian ini adalah $62 \%$ dari seluruh kasus stenosis mitral (SM), mayoritas pasien SMR memiliki stenosis derajat berat (rerata MVA $1 \pm 0,5 \mathrm{~cm}^{2}$ ). Pasien SMR mayoritas adalah perempuan, berusia 31-40 tahun (rerata 39,7 $\pm 12,8$ ), tidak bekerja, berpendidikan terakhir SMA, memiliki keluhan utama dispnea, dan memiliki NYHA functional class II. Seluruh pasien menerima pengobatan medis dan hanya enam pasien yang menjalani BMV atau operasi. Komplikasi yang paling banyak diderita pasien SMR adalah hipertensi pulmonal dan kelainan katup reumatik lain yang paling sering menyertai SMR adalah regurgitasi mitral. Simpulan studi ini ialah terdapat kesamaan karakteristik pasien SMR pada penelitian ini dengan tren karakteristik dari negara berkembang lainnya.
\end{abstract}

Kata kunci: stenosis mitral reumatik, karakteristik dasar, karakteristik klinis, karakteristik ekokardiografi

\begin{abstract}
Rheumatic Heart Disease (RHD) remains high in prevalence and rate of morbidity and mortality in developing countries including in Indonesia. Rheumatic Mitral Stenosis (RMS) is one of the most frequent valve disease in RHD, yet not many studies about RMS are available in Indonesia. The objective of this study was to describe the profile of RMS patients in Dr. M. Djamil Hospital Padang in 2012 until 2016. This was a descriptive study with a retrospective approach and was performed from September 2017 until January 2018 in Dr. M. Djamil Hospital Padang. The medical record which met the inclusion criteria were collected to be the sample by total sampling technique. The proportion of RMS was $62 \%$ of all mitral stenosis (MS) cases, and most of them had severe MS (mean MVA $1 \pm 0,5 \mathrm{~cm}^{2}$ ). Most of the RMS patients were female, aged 31-40 years old (mean 39,7 $\pm 12,8$ ), unemployed, and high-school student/graduated, came with dyspnea and had NYHA functional class II. All patients received medical treatment and only six patients underwent BMV or surgery. Pulmonary hypertension was the most common complication and mitral regurgitation was the most frequent rheumatic valve lesion accompanied RMS. The conclusion is the characteristics of RMS patients in this study were similar with those from other developing countries.
\end{abstract}

Keywords: rheumatic mitral stenosis, basic characteristic, clinical characteristic, echocardiographic characteristic

Affiliasi penulis: 1. Prodi Kedokteran Fakultas Kedokteran Universitas Andalas (FK Unand) Padang; 2. Bagian Kardiologi dan Kedokteran Vaskular FK Unand/RSUP Dr. M. Djamil Padang; 3. Bagian Neurologi FK Unand/RSUP Dr. M. Djamil Padang
Korespondensi: Mentari Brillianti Permataranny

Email: mentari.brillianti@gmail.com, Telp: 081291725757 


\section{PENDAHULUAN}

Demam Reumatik (DR) dan Penyakit Jantung Reumatik (PJR) masih menjadi salah satu masalah besar di bidang kesehatan di dunia, terutama di negara berkembang di Asia dan Afrika, dan telah menjadi perhatian WHO selama 5 dekade terakhir. Penyakit ini dapat dicegah dengan menggunakan strategi yang relatif murah dan efektif biaya, serta praktikal bagi negara berkembang, namun penyakit ini masih memiliki prevalensi, morbiditas, dan mortalitas yang tinggi terutama di kalangan anak dan dewasa muda (usia produktif), dan apabila hal ini terus berlanjut, kualitas sumber daya manusia di masa mendatang akan terpengaruh. ${ }^{1-2}$ Stenosis Mitral (SM) merupakan kelainan katup terbanyak pada PJR, terutama pada fase kronis, dan sebaliknya, DR masih menjadi penyebab utama $\mathrm{SM}^{3-5}$ Data penelitian yang tersedia mengenai Stenosis Mitral Reumatik (SMR) terutama di Indonesia masih sangat minim.

Diperkirakan terdapat 15,6-19,6 juta penduduk dunia menderita PJR, dengan jumlah kematian diperkirakan mencapai 233.000-294.000 orang per tahun, dan sekitar $79 \%$ kasus berasal dari negara berkembang. ${ }^{6}$ Jumlah penderita PJR di Asia diestimasi mencapai 10,8-15,9 juta orang dengan jumlah kematian sebanyak $356.000-534.000$ orang per tahun. ${ }^{2}$ Menurut World Health Organization (WHO), jumlah kematian akibat PJR di Asia Tenggara pada tahun 2000 diperkirakan 117.000 orang. Angka disabilitas per tahun (disability-adjusted life years/DALYs) akibat PJR di wilayah Amerika yaitu sekitar 27,4 per 100.000, sedangkan di wilayah Asia Tenggara mencapai 173,4 per $100.000 .{ }^{1}$

Penyakit jantung reumatik hampir selalu melibatkan katup mitral, dan stenosis merupakan lesi yang predominan, terutama pada fase kronis. ${ }^{4,7}$ Salah satu penelitian di Papua, Indonesia terhadap populasi pekerja tambang yang menderita PJR di Papua menunjukkan bahwa kelainan katup terbanyak akibat pada PJR adalah SM $(41,0 \%){ }^{4}$

Stenosis mitral reumatik kerap ditemukan pada daerah dengan prevalensi DR dan PJR yang tinggi, yaitu daerah dengan keadaan sosioekonomi masyarakat yang rendah (berhubungan dengan kemiskinan, overcrowding, malnutrisi, dan sulitnya akses ke sarana atau jasa pelayanan kesehatan), serta kondisi lingkungan yang kurang bersih. ${ }^{1}$ Tren karakteristik pasien SMR di negara maju dan di negara berkembang cenderung berbeda.

Stenosis mitral reumatik lebih sering terjadi pada perempuan dibandingkan pada laki-laki dengan perbandingan antara perempuan dan laki-laki mencapai 3:1, dan hal tersebut didukung oleh berbagai hasil penelitian di dunia., ${ }^{3,7}$ Pasien SMR rata-rata adalah pasien dewasa berusia 20-40 tahun. Salah satu hasil penelitian multiregional di dunia menunjukkan bahwa usia rerata pasien SMR di 5 negara berkembang adalah $35 \pm 12$ tahun (lebih muda dibandingkan rerata usia di 2 negara maju yang ikut diteliti yaitu $57 \pm 15$ tahun). ${ }^{8}$ Sedangkan rentang usia terbanyak pasien SMR di kalangan pekerja tambang di Papua, Indonesia adalah 35-44 tahun. ${ }^{4}$

Derajat SMR di negara berkembang pun cenderung lebih berat dibandingkan dengan di negara maju. Salah satu hasil penelitian multiregional di dunia pada tahun 2008 menunjukkan bahwa pasien SMR di negara berkembang memiliki rerata Mitral Valve Area (MVA) yang lebih kecil yaitu 0,91 $\pm 0,23 \mathrm{~cm}^{2}$ dibandingkan dengan di negara maju (MVA 1,05 $\pm 0,22$ $\left.\mathrm{cm}^{2}\right)^{8}$

Stenosis mitral reumatik memiliki komplikasi yang dapat menurunkan kualitas hidup pasien dan mengancam jiwa/ life-threatening. Hipertensi pulmonal (HP) merupakan komplikasi yang paling sering terjadi pada pasien SMR di negara berkembang, sedangkan di negara maju, fibrilasi atrium (FA) merupakan komplikasi terbanyak. ${ }^{8}$ Beberapa komplikasi SMR lainnya yaitu terbentuknya trombus jantung, terjadinya tromboemboli, dan bahkan kematian., 3,5,10

Angka kejadian, morbiditas, dan mortalitas SMR masih tinggi di negara berkembang termasuk Indonesia, namun data penelitian tentang penyakit SMR di Indonesia masih sangat minim. Sebagai Pusat Jantung Regional, RSUP Dr. M. Djamil Padang pun belum memiliki data publikasi mengenai profil penderita SMR. Berdasarkan uraian latar belakang tersebut, maka peneliti merasa perlu melakukan penelitian mengenai profil penderita SMR di RSUP Dr. M. Djamil Padang pada tahun 2012-2016. 


\section{METODE}

Jenis penelitian yang digunakan adalah studi deskriptif dengan pendekatan retrospektif. Penelitian ini dilakukan di Instalasi Pusat Pelayanan Jantung Terpadu dan Instalasi Rekam Medik RSUP Dr. M. Djamil Padang yang berlangsung dari bulan September 2017 hingga Januari 2018.

Seluruh populasi pasien stenosis mitral reumatik (SMR) di RSUP Dr. M. Djamil Padang pada tahun 2012-2016 yang memenuhi kriteria inklusi penelitian dijadikan sebagai sampel penelitian dengan menggunakan teknik pengambilan sampel total sampling. Kriteria inklusi pada penelitian ini adalah rekam medis pasien SMR dengan data yang lengkap sesuai dengan kebutuhan penelitian. Kriteria eksklusi pada penelitian ini adalah sebagai berikut:

1. Pasien SMR dengan penyakit jantung kongenital.

2. Pasien SMR yang sebelumnya sudah pernah menjalani tindakan intervensi mekanis terhadap katup mitral.

Data yang diperoleh akan dianalisis dan disajikan dalam bentuk tabel distribusi frekuensi dan dalam bentuk narasi.

\section{HASIL}

Periode tahun 2012 hingga 2016, didapatkan 121 nomor rekam medis pasien Stenosis Mitral (SM), dan sebagian besar di antaranya (62\%) merupakan kasus SMR (Tabel 1). Namun, dari 75 rekam medis pasien SMR yang ditemukan, 28 di antaranya tidak memenuhi kriteria inklusi penelitian ini, sehingga total sampel penelitian yang digunakan pada penelitian ini berjumlah 47 rekam medis.

Tabel 1. Proporsi penyebab reumatik pada populasi stenosis mitral (SM)

\begin{tabular}{lcc}
\hline \multicolumn{1}{c}{ Penyebab SM } & $\mathbf{n}$ & $\%$ \\
\hline Reumatik & 75 & 62 \\
Non-reumatik & 46 & 38 \\
Total & 121 & 100 \\
\hline
\end{tabular}

Pada Tabel 2 dapat dilihat bahwa dalam penelitian ini, sebagian besar pasien SMR menderita stenosis derajat berat $(51,1 \%)$. Pasien dengan derajat stenosis ringan hanya meliputi sebagian kecil dari populasi SMR.

Tabel 2. Distribusi frekuensi dan persentase derajat stenosis mitral reumatik

\begin{tabular}{lcc}
\hline Derajat SMR & $\mathbf{n}$ & $\%$ \\
\hline Ringan & 7 & 14,9 \\
Sedang & 16 & 34 \\
Berat & 24 & 51,1 \\
Total & 47 & 100 \\
\hline
\end{tabular}

Berdasarkan karakteristik dasar dan klinis (Tabel 3), SMR paling banyak diderita oleh perempuan (72,3\%). Secara umum, mayoritas pasien SMR adalah pasien dewasa dengan rentang usia 21-40 tahun, namun, dalam rentang usia tersebut, jumlah pasien SMR paling banyak berada pada kelompok usia 31-40 tahun (rerata usia 39,7 $\pm 12,8$ tahun). Sebagian besar pasien SMR tidak bekerja (66\%), selain itu pendidikan terakhir mayoritas pasien SMR adalah SMA (57,4\%). Dispnea/sesak napas merupakan keluhan yang paling banyak dikeluhkan pasien (76,6\%) dan sebagian besar pasien SMR pada penelitian ini memiliki NYHA functional class II (59,6\%). Seluruh pasien SMR diberikan tatalaksana berupa pemberian obat, dan hanya 6 orang pasien SMR yang menjalani tatalaksana mekanis berupa balloon mitral valvotomy (BMV) ataupun operasi, dan seluruhnya merupakan pasien dengan derajat SMR berat. Jenis komplikasi yang dialami pasien SMR sangat bervariasi, namun hipertensi pulmonal (HP) (76,6\%) dan fibrilasi atrium (FA) $(63,8 \%)$ merupakan dua komplikasi yang paling umum diderita pasien SMR. Sebanyak 31 dari 47 pasien SMR menderita komplikasi multipel, dan sebagian besar di antaranya menderita kombinasi antara $\mathrm{HP}+\mathrm{FA}$, dengan atau tanpa disertai komplikasi lain. 
Tabel 3. Karakteristik dasar dan karakteristik klinis pasien stenosis mitral reumatik

\begin{tabular}{|c|c|c|c|c|c|}
\hline \multirow{2}{*}{$\begin{array}{c}\text { Karakteristik } \\
\text { Dasar }\end{array}$} & \multicolumn{5}{|c|}{ Derajat SMR } \\
\hline & $\begin{array}{c}\text { Ringan } \\
(n=7)\end{array}$ & $\begin{array}{l}\text { Sedang } \\
(n=16)\end{array}$ & $\begin{array}{c}\text { Berat } \\
(n=24)\end{array}$ & \multicolumn{2}{|c|}{$\begin{array}{l}\text { Total } \\
(\mathrm{N}=47)\end{array}$} \\
\hline \multicolumn{2}{|l|}{ Jenis Kelamin, $n(\%)$} & & & & \\
\hline Laki-laki & $2(4,3)$ & $1(2,1)$ & $10(21,3)$ & 13 & $(27,7)$ \\
\hline Perempuan & $5(10,6)$ & $15(31,9)$ & $14(29,8)$ & 34 & $(72,3)$ \\
\hline \multicolumn{6}{|l|}{ Usia, n (\%) } \\
\hline$\leq 20$ tahun & $0(0,0)$ & $0(0,0)$ & $1(2,1)$ & 1 & $(2,1)$ \\
\hline 21-30 tahun & $2(4,3)$ & $4(8,5)$ & $6(12,8)$ & 12 & $(25,5)$ \\
\hline 31-40 tahun & $3(6,4)$ & $3(6,4)$ & $7(14,9)$ & 13 & $(27,7)$ \\
\hline 41-50 tahun & $2(4,3)$ & $3(6,4)$ & $4(8,5)$ & 9 & $(19,1)$ \\
\hline 51-60 tahun & $0(0,0)$ & $4(8,5)$ & $5(10,6)$ & 9 & $(19,1)$ \\
\hline$>60$ tahun & $0(0,0)$ & $2(4,3)$ & $1(2,1)$ & 3 & $(6,4)$ \\
\hline Usia, mean $\pm S D$ & $36,1 \pm 9,2$ & $42,4 \pm 13,8$ & $39,0 \pm 13,2$ & $39,7=$ & $=12,8$ \\
\hline \multicolumn{6}{|l|}{ Pekerjaan, n (\%) } \\
\hline Tidak bekerja & $4(8,5)$ & $14(29,8)$ & $13(27,7)$ & 31 & (66) \\
\hline Bekerja & $3(6,4)$ & $2(4,3)$ & $11(23,4)$ & 16 & (34) \\
\hline \multicolumn{6}{|l|}{ Pendidikan, n (\%) } \\
\hline SD & $1(2,1)$ & $6(12,8)$ & $2(4,3)$ & 9 & $(19,1)$ \\
\hline SMP & $0(0,0)$ & $1(2,1)$ & $1(2,1)$ & 2 & $(4,3)$ \\
\hline SMA & $4(8,5)$ & $7(14,9)$ & $16(34)$ & 27 & $(57,4)$ \\
\hline PT/Akademi & $2(4,3)$ & $2(4,3)$ & $5(10,6)$ & 9 & $(19,1)$ \\
\hline \multicolumn{6}{|l|}{ Keluhan utama, $\mathrm{n}(\%)$} \\
\hline Asimptomatis & $2(4,3)$ & $2(4,3)$ & $0(0,0)$ & 4 & $(8,5)$ \\
\hline Dispnea & $5(10,6)$ & $10(21,3)$ & $21(44,7)$ & 36 & $(76,6)$ \\
\hline Palpitasi & $0(0,0)$ & $2(4,3)$ & $1(2,1)$ & 3 & $(6,4)$ \\
\hline Nyeri dada & $0(0,0)$ & $1(2,1)$ & $0(0,0)$ & 1 & $(2,1)$ \\
\hline Suara serak & $0(0,0)$ & $1(2,1)$ & $0(0,0)$ & 1 & $(2,1)$ \\
\hline \multicolumn{6}{|c|}{ NYHA functional class, $\mathrm{n}(\%)$} \\
\hline Class I & $1(2,1)$ & $2(4,3)$ & $0(0,0)$ & 3 & $(6,4)$ \\
\hline Class II & $5(10,6)$ & $9(19,1)$ & $14(29,8)$ & 28 & $(59,6)$ \\
\hline Class III & $1(2,1)$ & $2(4,3)$ & $7(14,9)$ & 10 & $(21,3)$ \\
\hline Class IV & $0(0,0)$ & $3(6,4)$ & $3(6,4)$ & 6 & $(12,8)$ \\
\hline \multicolumn{6}{|l|}{ Tatalaksana, n (\%) } \\
\hline Medikamentosa & $7(14,9)$ & $17(36,2)$ & $23(48,9)$ & 47 & $(100)$ \\
\hline Mekanis & $0(2,1)$ & $0(0,0)$ & $6(12,8)$ & 6 & $(12,8)$ \\
\hline \multicolumn{6}{|l|}{ Komplikasi, n (\%) } \\
\hline Fibrilasi atrium & $3(6,4)$ & $10(21,3)$ & $17(36,2)$ & 30 & $(63,8)$ \\
\hline Hipertensi pulmonal & $3(6,4)$ & $11(23,4)$ & $22(46,8)$ & 36 & $(76,6)$ \\
\hline Trombus jantung & $0(0,0)$ & $3(6,4)$ & $6(12,8)$ & 9 & $(19,1)$ \\
\hline Trombo-emboli & $0(0,0)$ & $1(2,1)$ & $3(6,4)$ & 4 & $(8,5)$ \\
\hline Meninggal & $0(0,0)$ & $1(2,1)$ & $3(6,4)$ & 4 & $(8,5)$ \\
\hline
\end{tabular}




\section{PEMBAHASAN}

\section{Proporsi Stenosis Mitral Reumatik}

Sebagian besar kasus stenosis mitral (SM) di RSUP Dr. M. Djamil Padang pada tahun 2012-2016 disebabkan oleh proses reumatik (stenosis mitral reumatik/SMR) dengan persentase mencapai $62 \%$. Begitu pula di India Selatan, SM hampir secara eksklusif disebabkan oleh DR. ${ }^{11}$ Demam reumatik (DR) yang menyebabkan penyakit jantung reumatik (PJR) masih menjadi penyebab utama terjadinya SM, terutama di negara-negara berkembang dimana tingkat kejadian DR masih tinggi. ${ }^{3,10}$ Tingginya kejadian SMR di negara berkembang secara umum berhubungan dengan keadaan sosioekonomi masyarakat yang cenderung rendah (kemiskinan, overcrowding, malnutrisi, akses ke pelayanan kesehatan sulit), rendahnya pengetahuan, pemahaman, dan kewaspadaan masyarakat terhadap penyakit, higienitas dan sanitasi masyarakat yang kurang baik, serta kurangnya sumber daya, ataupun kualitas, di bidang pelayanan kesehatan. ${ }^{1,12}$

Di negara maju, SM lebih banyak disebabkan oleh penyebab degeneratif. ${ }^{13}$ Beberapa penelitian di negara maju (dan negara emerging) menunjukkan masih tingginya persentasi DR dan PJR sebagai penyebab terjadinya SM..$^{13-14}$ Salah satu hal yang mungkin mempengaruhi tingginya persentase etiologi DR pada kasus SM di negara maju yaitu cukup tingginya populasi imigran yang berasal dari negara dengan angka kejadian PJR yang masih tinggi. ${ }^{15}$

\section{Derajat Stenosis Mitral Reumatik}

Pasien SMR di RSUP Dr. M. Djamil Padang tahun 2012-2016 didominasi oleh pasien dengan derajat stenosis berat $(51,1 \%)$, diikuti dengan derajat stenosis sedang, dan ringan. Hal ini serupa dengan hasil penelitian yang dilakukan di India Selatan yang menunjukkan bahwa mayoritas pasien SMR yang diteliti memiliki derajat stenosis berat $(47,2 \%){ }^{11}$

Stenosis mitral reumatik adalah penyakit dengan progresifitas lambat, dan kondisi asimptomatis pada pasien dapat berlangsung selama puluhan tahun. ${ }^{9}$ Gejala yang timbul akibat dipicu aktivitas ringan atau sedang, atau bahkan saat pasien beristirahat sekalipun, biasanya dialami oleh pasien SM yang telah memiliki stenosis derajat sedang hingga berat, dan kemungkinan besar pada saat inilah mayoritas pasien mulai datang memeriksakan diri ke dokter. $^{5}$

\section{Karakteristik Dasar dan Klinis}

\section{- Jenis Kelamin}

Pasien SMR pada penelitian ini paling banyak berjenis kelamin perempuan $(72,3 \%)$. Hal yang sama ditunjukkan dari berbagai hasil penelitian tentang SMR yang dilakukan di berbagai negara di dunia., ${ }^{7,8,11}$ Penyebab kecenderungan SMR terjadi pada perempuan hingga saat ini belum dapat dijelaskan dengan pasti, namun, terdapat pendapat yang menyatakan bahwa kecenderungan tersebut kemungkinan berhubungan dengan faktor genetika atau kerentanan individu terhadap DR, serta tingginya paparan bakteri streptokokus $\beta$-hemolitikus grup $A$ (SBHGA) terhadap perempuan, akibat besarnya keterlibatan perempuan dalam aktivitas mengasuh anak karena angka kejadian DR sangatlah tinggi pada anak-anak. $^{8,12,16}$

\section{- Usia}

Usia rerata pasien SMR pada penelitian ini adalah $39,7 \pm 12,8$ tahun. Sebagian besar pasien SMR berusia 21-40 tahun, namun pasien SMR paling banyak berada dalam rentang usia 31-40 tahun $(27,7 \%)$. Salah satu penelitian tentang SMR yang dilakukan berdasarkan data dari beberapa negara berkembang di dunia menunjukkan usia rerata pasien SMR yang diteliti yaitu $35 \pm 12$ tahun. ${ }^{8}$ Hasil penelitian yang dilakukan di India Selatan menunjukan bahwa pasien SMR paling banyak berada pada rentang usia 30-39 tahun. ${ }^{11}$ Namun, penelitian lain di negara maju menunjukkan rerata usia yang lebih tinggi/tua yaitu $57 \pm 15$ tahun (di beberapa negara maju) dan $68 \pm 11$ tahun (di Liverpool). ${ }^{8,13}$

Secara umum dibutuhkan waktu 20-40 tahun (periode laten) sejak infeksi reumatik awal, hingga munculnya gejala SMR yang signifikan. ${ }^{1,5,10}$ Hal tersebut mungkin dapat menjadi alasan banyaknya pasien SMR berada pada rentang usia 20-40 tahun pada penelitian ini dan pada beberapa penelitian lainnya. Namun, di negara berkembang, dimana angka kejadian DR dan PJR masih sangat tinggi, perjalanan penyakit SMR cenderung berlangsung 
lebih cepat dan lebih berat dibandingkan dengan di negara maju. Keadaan tersebut dipengaruhi oleh kualitas prevensi atau utilisasi antibiotik terhadap DR dan PJR, virulensi strain bakteri, frekuensi serangan DR berulang, faktor genetika, serta kondisi lingkungan tempat tinggal yang mempermudah transmisi bakteri (overcrowding dan kurangnya higienitas dan sanitasi), serta cepat atau lambatnya waktu diagnosis. ${ }^{5,8-9}$

\section{- Pekerjaan}

Sebanyak 31 pasien SMR (66\%) pada penelitian ini tidak bekerja dan sebagian besar pasien yang tidak bekerja adalah ibu rumah tangga. Hal serupa ditunjukkan oleh hasil penelitian di Afrika dimana sekitar 2 per 3 pasien PJR tidak bekerja (atau ibu rumah tangga). ${ }^{17-18}$ Pada penelitan ini, kami mengaitkan status pekerjaan dengan rendahnya pendapatan ataupun status sosioekonomi pasien, meskipun status memiliki pekerjaan tidak menjamin tingginya pendapatan pasien, karena tingginya prevalensi DR dan PJR sangat dipengaruhi oleh status sosioekonomi masyarakat. ${ }^{1,12,19}$

\section{- Pendidikan}

Mayoritas pasien SMR pada penelitian ini memiliki pendidikan terakhir SMA $(57,4 \%)$, diikuti dengan SD dan perguruan tinggi (PT)/akademi (masing-masing 19,1\%), dan SMP (4,3\%). Hasil penelitian di Afrika menunjukkan bahwa mayoritas pasien PJR yang diteliti memiliki tingkat pendidikan terakhir sekolah menengah/secondary level. ${ }^{17}$ Penelitian lain di Afrika bahkan menyebutkan mayoritas pasien PJR yang diteliti tidak mengikuti pendidikan formal atau hanya tamat sekolah dasar. ${ }^{18}$

Tingkat pendidikan pasien kami kaitkan dengan pengetahuan dan pemahaman terhadap kesehatan penyakit secara umum termasuk DR dan PJR, mulai dari penyebab, pencegahan, hingga pengobatan penyakit. Wawasan dan kesadaran masyarakat terhadap kesehatan dan penyakit merupakan faktor paling penting dalam upaya pencegahan primordial PJR dan SMR. ${ }^{19-20}$

\section{- Keluhan Utama}

Berdasarkan keluhan utama, sebanyak 76,6\% pasien SMR mengeluh mengalami sesak napas/dispnea, sebanyak $8,5 \%$ asimptomatis, dan $14,9 \%$ lainnya mengalami palpitasi, nyeri dada, suara sesak, dan lumpuh anggota gerak akibat kardioemboli serebri. Pada tahun 2001, The Euro Heart Survey melakukan penelitian mengenai SM di negara-negara di Eropa, dan hasil penelitian tersebut menunjukkan bahwa $78,6 \%$ pasien dari 336 pasien mengalami gejala dispnea. ${ }^{21}$

Berdasarkan berbagai sumber literatur, dispnea merupakan keluhan utama yang paling sering terjadi pada pasien dengan stenosis mitral, terutama dispnea eksersional. $^{3,5,9}$ Dispnea pada pasien dengan SM disebabkan oleh terjadinya penurunan cardiac output akibat penurunan preload ventrikel kiri, serta disebabkan oleh kongesti paru dan bahkan disfungsi jantung kanan akibat transmisi retrograde aliran dan tekanan darah dari atrium kiri. $^{3,9}$

\section{NYHA Functional Class}

Pada penelitian ini, mayoritas pasien SMR memiliki functional class II (59,6\%), di seluruh kelompok derajat SMR, dan diikuti dengan functional class III (21,3\%). Hasil penelitian yang dilakukan di India, dan di Perancis, menunjukkan hal sejalan. ${ }^{7,22}$ Namun, penelitian lain menunjukkan hal berbeda, yaitu mayoritas pasien SMR yang diteliti memiliki NYHA functional class III. $^{14}$ Perbedaan pada hasil penelitian tersebut mungkin disebabkan oleh karena NYHA functional class merupakan penilaian kemampuan fungsional pasien yang ditetapkan secara subjektif dan dipengaruhi oleh banyak hal seperti waktu penetapan diagnosis, dan medikasi atau intervensi yang telah diberikan kepada pasien SMR. ${ }^{9,14,22}$

\section{Tatalakasana}

Seluruh pasien SMR pada penelitian ini diberikan tatalaksana berupa pemberian medikasi dan hanya 6 orang pasien SMR (12,8\%) derajat berat yang 
menjalani tatalaksana mekanis (tiga orang pasien menjalani operasi, dua orang pasien menjalani balloon mitral valvotomy/BMV, dan satu orang pasien menjalani operasi dan BMV). Salah satu penelitian terdahulu di Eropa menunjukkan 44,4\% pasien SM yang diteliti menjalani tatalaksana mekanis, mayoritas berupa operasi mitral valve replacement (MVR) $(61,1 \%)$, dan diikuti oleh BMV $(33,9 \%){ }^{21}$

Stenosis mitral hanya dapat ditatalaksana secara definitif menggunakan tatalaksana mekanis dan BMV merupakan intervensi non invasif pilihan karena BMV terbukti lebih superior dibandingkan tatalaksana operasi (terbuka maupun tertutup). ${ }^{3,8}$ Pada hasil penelitian ini dan penelitian serupa lainnya, pasien SMR yang menjalani tindakan operasi lebih banyak dari pasien yang menjalani tindakan BMV. Hal tersebut mungkin disebabkan oleh karena pasien tersebut tidak memenuhi kriteria dilakukannya BMV. Selain itu, di RSUP Dr. M. Djamil Padang, tindakan BMV baru rutin dilakukan pada tahun 2017.

Pada penelitian ini juga terdapat 12 orang pasien SMR yang telah direkomendasikan untuk menjalani operasi, namun akibat keterbatasan data pada sebagian besar rekam medis, tidak terdapat keterangan lebih lanjut apakah pasien menerima dan melaksanakan anjuran tersebut, atau menolaknya. Namun, 2 orang pasien terdata menolak rekomendasi tindakan operasi. Hal tersebut disebabkan oleh karena tindakan operasi katup mitral belum bisa dilakukan di Padang (dirujuk ke Jakarta). Selain jaraknya yang jauh, finansial juga menjadi alasan pasien menolak rekomendasi tindakan dari dokter spesialis jantung.

\section{- Komplikasi}

Sebagian besar pasien SMR pada penelitian ini (66\%) memiliki komplikasi multipel dan kombinasi berupa hipertensi pulmonal (HP) dan fibrilasi atrium (FA) merupakan jenis komplikasi multipel terbanyak. Hipertensi Pulmonal (HP) dan Fibrilasi Atrium (FA) pun merupakan dua jenis komplikasi yang paling banyak ditemukan pada pasien SMR. ${ }^{23}$

Komplikasi berupa Hipertensi Pulmonal (HP) merupakan komplikasi terbanyak pada penelitian ini (76,6\%), dan penelitian lainnya yang dilakukan di India dan di Semarang, Indonesia pun menunjukkan hal sejalan. ${ }^{24-25}$ Persentase kejadian HP pada penelitian ini pun meningkat seiring bertambahnya derajat stenosis pasien, dan hal ini didukung oleh hasil penelitian di Semarang, Indonesia, yang menyatakan bahwa terdapat korelasi negatif kuat antara mitral valve area (MVA) dengan $\mathrm{HP} .^{25}$

Hipertensi pulmonal (HP) pada SM disebabkan oleh peningkatan tekanan atrium kiri yang persisten sebagai akibat dari penyempitan pada katup mitral. Hal tersebut kemudian akan menyebabkan peningkatan tekanan vena pulmonal dan kapiler pulmonal secara pasif (transmisi retrograde) yang pada akhirnya akan menimbulkan hipertensi arteri pulmonal, serta perubahan struktur dan hemodinamik pada jantung kanan. ${ }^{3,5,9}$

Fibrilasi Atrium (FA) diderita oleh 63,8\% pasien SMR pada penelitian ini. Persentase komplikasi FA pada pasien SM berdasarkan penelitian yang dilakukan di Semarang, Indonesia bahkan mencapai $71,4 \%$. Fibrilasi Atrium (FA) pada SMR disebabkan penurunan stabilitas elektrik atrium kiri akibat peningkatan tekanan atrium kiri kronik. ${ }^{5}$ Gangguan kontraksi atrium pada FA menyebabkan aliran darah di dalam atrium kiri menjadi lebih stasis dan hal ini menjadi salah satu faktor utama terbentuknya trombus atrium kiri yang dapat menimbulkan komplikasi berbahaya lainnya yaitu tromboemboli. ${ }^{9,23}$

\section{SIMPULAN}

Pasien SMR pada penelitian ini memiliki karakteristik dasar, klinis, dan ekokardiografi yang bervariasi. Secara umum karakteristik pasien SMR pada penelitian ini memiliki kesamaan dengan tren karakteristik pasien SMR dari negara berkembang lainnya.

\section{DAFTAR PUSTAKA}

1. World Health Organization (WHO). WHO technical report series: rheumatic fever and rheumatic heart disease. WHO [online] 2004 (diunduh Desember 2016). Tersedia dari: http://apps.who.int/iris/ bitstream/10665/42898/1/WHO TRS 923.pdf

2. Carapetis JR. Rheumatic heart disease in Asia. Circ. 2008;118:2748-53.

3. Carabello BA. Mitral stenosis. Dalam: Fuster V, Walsh RA, editor (penyunting). Hurst's the heart 
volume 1. Edisi ke-13. New York: McGraw-Hill; 2011.hlm.1738-43.

4. Rodriguez-Fernandez $R$, Amiya $R$, Wyber $R$, Widdodow W, Carapetis J. Rheumatic heart disease among adults in mining community of Papua, Indonesia: findings from an occupational cohort. Heart Asia. 2015;7:1-5.

5. Enriquez-Sarano ML, Frye RL. Mitral Valve Disease. Dalam: Willerson JT, Cohn JN, editor (penyunting). Cardiovascular medicine. Edisi ke-3. London: Springer-Verlag; 2007.hlm.398-402.

6. Carapetis JR, Andrew CS, Mulholland EK, Weber M. The Global burden of group A Streptococcal Disease. Lancet Infect Dis. 2005 Nov;5:685-94.

7. Ramakrishna CD, Khadar SA, George R, Jayaprakash VL, Sudhayakumar N, Jayaprakash $\mathrm{K}$, et al. The Age-specific clinical and anatomical profile of mitral stenosis. Singapore Med J. 2009;50(7):680-4

8. Marijon E, Lung B, Mocumbi AO, Kamblock J, Thanh CV, Gamra $\mathrm{H}$, et al. What are the differences in presentation of candidates for percutaneous mitral commissurotomy across the world and do they influence the result of the procedure? Arch Cardiovasc Dis. 2008;101:611-7.

9. Indrajaya T, Ghanie A. Stenosis mitral. Dalam: Sudoyo AW, Setiyohadi B, editor (penyunting). Buku ajar ilmu penyakit dalam jilid I. Jakarta: Pusat Penerbitan Departemen IImu Penyakit Dalam FKUI; 2014.hlm.1171-87.

10. Laudari S, Subramanyam G. A Study df spectrum of rheumatic heart disease in a tertiary care hospital in central Nepal. Int J Cardiol Heart Vasc. 2017;15:26-30.

11. Manjunath $\mathrm{CN}$, Srinivas $\mathrm{P}$, Ravindranath $\mathrm{KS}$, Dhanalakshmi C. Incidence and patterns of valvular heart disease in a tertiary care highvolume cardiac center: a single center experience. Indian Heart J. 2014;66:320-6.

12. Rizvi SF, Khan MA, Kundi A, Marsh DR, Samad A, Pasha O. Status of rheumatic heart disease in rural Pakistan. Heart. 2004;90:394-9.

13. Akram MR, Chan T, McAullife S, Chenzbraun A. Non-rheumatic annular mitral stenosis: prevalence and characteristics. Eur J Echocardiogr. 2009 Jun 9;10:103-5.
14. Demirbag R, Sade LE, Aydm M, Bozkurt A, Acarturk $\mathrm{E}$. The Turkish registry of heart valve disease. Arch Turk Soc Cardiol. 2013;41(1):1-10.

15. Abul-Fadl AM, Mourad MM, Ghamrawy A, Sarhan $A E$. Trends in deaths from rheumatic heart disease in the eastern mediterranean region: burden and challenge. J Cardiovasc Dev Dis. 2018:5(32);1-13.

16. Sani MU, Karaye KM, Borodo MM. Prevalence and pattern of rheumatic heart disease in the Nigerian Savannah:an echocardiographic study. Cardiovasc J Afr. 2007;18(5):295-9.

17. Zuhlke L, Engel ME, Karthiyekan G, Rangarajan S, Mackie P, Cupido B, et al. Characteristics, complications, and gaps in evidence-based interventions in rheumatic heart disease: the global rheumatic heart disease registry (the Remedy study). Eur Heart J. 2015;36:1115-22.

18. Kingue S, Abdou S, Balde D, Diarra MB, AnzouanKacou JB, Anisubiar B, et al. The VALVARIC study: a registry of rheumatic heart disease in western and central Africa. Arch Cardiovasc Dis. 2016;109:321-9.

19. Kumar RK, Tandon R. Rheumatic fever \& rheumatic heart disease: the last 50 years. Indian $\mathrm{J}$ Med Res. 2013 Apr;137: 643-58.

20. Carapetis J, Brown A, Maguire G, Walsh W, Noonan S, Thompson D. The Australian guideline for prevention, diagnosis, and management of acute rheumatic fever and rheumatic heart disease. RHD Australia. Edisi ke-2; 2012.hlm.11102.

21. lung B, Baron G, Tornos P, Gohlke-Barwolf C, Butchart EG, Vahanian A. Valvular heart disease in the community: a European experience. Curr Probl Cardiol. 2007 Nov;32:609-61.

22. Deswarte G, Richardson M, Polge AS, Pouwels S, Ennezat PV, Trochu JN, et al. Longitudinal right ventricular as a predictor of functional capacity in patients with mitral stenosis: an exercise echocardiographic study. J Am Soc Echocardiogr. 2010;23(6):667-72.

23. Riaz A, Kaleem M, Abbas H. Frequency of different complications of mitral stenosis. J Cardiovasc Dis. 2015;13(3):81-4 .

24. Ramakrishna CD, Kanattu PS. Echocardiographic and clinical evaluation of rheumatic mitral stenosis 
in younger and elderly patients. Int $\mathrm{J}$ Clin Med. 2017 Mar 15;8:128-35.

25. Setiawan F, Uddin I, Sofia SN. Hubungan mitral valve area (MVA) dengan hipertensi pulmonal pada stenosis mitral (skripsi). Semarang: Program Pendidikan Sarjana Kedokeran Fakultas Kedokteran Universitas Dipenogoro; 2014. 